\title{
PENGUATAN STRATEGI PEMASARAN PUDAK DI TENGAH PANDEMI COVID-19 UNTUK MENINGKATKAN KEUNGGULAN BERSAING USAHA MIKRO KECIL MENENGAH KOTA GRESIK
}

\author{
Narto $^{1^{*}}$, Gatot Basuki HM ${ }^{2}$ \\ ${ }^{1}$ Program Studi Teknik Industri, Fakultas Teknik, Universitas Qomaruddin \\ 2Program Studi Teknik Industri, Fakultas Teknologi Industri, Institut Teknologi Adhi Tama Surabaya \\ Email: nartonazriel@gmail.com; gatotbasukihm@itats.ac.id
}

Artikel masuk : 01-05-2020 Artikel direvisi : 25-06-2020 Artikel diterima :29-06-2020

*Penulis Korespondensi

\begin{abstract}
Abstrak - Pudak merupakan makanan khas Kota Gresik yang menjadi Usaha Mikro Kecil Menengah (UMKM) yang sudah menjadi usaha turun temurun masyarakat kota Gresik. Adanya pandemi COVID 19 berdampak pada tingkat penjualan UMKM Pudak di Kota Gresik mengalami penurunan. Penelitian ini bertujuan untuk melakukan identifikasi terhadap faktor internal dan eksternal menggunakan pendekatan analisis SWOT dan melakukan perumusan strategi terpilih menggunakan Analytical Hierarchy Process (AHP). Penelitian ini menggunakan teknik purposive sampling dengan memberikan kuesioner kepada 50 responden yang terdiri dari pelaku UMKM, kelompok usaha, pemerintah dan konsumen Pudak Kota Gresik. Hasil analisis SWOT diperoleh nilai IFAS sebesar 2,7013 sedangkan nilai EFAS sebesar 2,9400. Dengan demikian matrik IE untuk UMKM Pudak Gresik berada di posisi pertumbuhan dan stabilitas. Hasil pemilihan strategi menggunakan metode AHP untuk menentukan strategi alternatif yaitu mempertahankan harga dan meningkatkan kualitas produk tanpa bahan pengawet untuk meningkatkan loyalitas konsumen terhadap produk dan memperoleh keuntungan yang menjanjikan, dengan nilai bobot sebesar 0,300. Prioritas kedua yaitu strategi melakukan promosi berbasis online dan memberikan diskon agar lebih dikenal luas dan menarik minat para konsumen diluar kota Gresik. Kedua strategi ini merupakan kombinasi yang dipilih untuk penguatan strategi pemasaran sehingga dapat meningkatkan keunggulan bersaing UMKM Pudak Gresik.
\end{abstract}

Kata kunci: AHP; Pudak; SWOT; UMKM

\begin{abstract}
Pudak is a typical food of Gresik City which is a Micro, Small, and Medium Enterprises (MSME) which has been a hereditary business for the people of Gresik. The existence of the COVID 19 pandemic has an impact on the level of sales of the Pudak MSMEs in Gresik City. This study aims to identify internal and external factors using the SWOT analysis approach and to formulate selected strategies using the Analytical Hierarchy Process (AHP). This study uses a purposive sampling technique by giving questionnaires to 50 respondents consisting of SMEs, business groups, government, and consumers of Pudak City Gresik. The SWOT analysis results obtained an IFAS value of 2.7013 while EFAS value of 2.9400. Thus IE matrix for Pudak Gresik SMEs is in a position of growth and stability. The results of the selection of strategies using the AHP method to determine alternative strategies, namely maintaining prices and improving product quality without preservatives to increase consumer loyalty to products and obtain promising benefits, with a weighting value of 0.300. The second priority is the strategy to do online-based promotions and give discounts to be more widely known and attract the interests of consumers outside the city of Gresik. These two strategies are the combination chosen for strengthening marketing strategies to increase the competitive advantage of SMEs Pudak Gresik.
\end{abstract}

Keywords: AHP; Pudak; SWOT; MSMES 


\section{PENDAHULUAN}

Usaha Mikro Kecil Menengah (UMKM) telah mampu memberikan kontribusi penting dalam peningkatan perekonomian Indonesia untuk itu pemberdayaan UMKM perlu dilakukan dengan serius (Putra \& Djazuli, 2013). Keterbatasan UMKM dalam mengakses informasi dan jangkauan pasar, jaringan tenaga kerja, serta akses lokasi strategis untuk usaha (Sutanto, Sudantoko, \& Maktub, 2012). Pudak adalah makanan khas kota Gresik. Makanan ini berbahan dasar dari tepung beras dan dibungkus pelepah daun lontar yang dikeringkan dan dijahit berbentuk kantong. Pudak yang memiliki bentuk dan kemasan yang mempunyai rasa yang khas. Dengan harga yang sangat terjangkau yaitu antara Rp. 2.500 sampai Rp. 5.000 rupiah per bungkusnya, makanan ini digemari sebagai oleholeh ketika berkunjung ke kota Gresik. Beberapa sentra industri UMKM yang tetap konsisten dalam usaha Pudak ini melakukan promosi dengan bekerjasama dengan pihak pengelola event yang diadakan oleh pemerintah kabupaten serta penjualan dengan membuka gerai yang ada di lokasi pariwisata, sentra kuliner dan juga memanfaatkan sistem daring.

Adanya wabah COVID-19 yang melanda dunia, mengakibatkan beberapa sektor industri termasuk Usaha Mikro Kecil Menengah (UMKM) di kota Gresik juga mengalami dampak turunnya tingkat penjualan sehingga keuntungan yang diperoleh hanya berkisar $7 \%$ dalam kurun waktu 1 bulan. Kondisi ini membutuhkan pemilihan strategi pemasaran melalui identifikasi faktor internal dan eksternal. Pemilihan strategi ini bertujuan meningkatkan keunggulan bersaing sehingga IKM dapat tetap bertahan dalam kondisi yang tidak menentu seperti saat ini. Keunggulan bersaing diperoleh melalui pengembangan kondisi internal dan eksternal sehingga diperoleh strategi bersaing yang tepat (Hartanto \& Kholil, 2018). Penentuan strategi pemasaran harus didasarkan atas analisis lingkungan eksternal dan internal perusahaan melalui analisis keunggulan dan kelemahan pada perusahaan, serta analisa kesempatan atau peluang dan ancaman yang dihadapi oleh perusahaan dari lingkungannya (Abdika, 2014). Strategi Pemasaran mampu mengubah fokus pemasaran dari pelanggan atau produk ke pelanggan, faktor lingkungan eksternal yang lebih luas yang menyangkut persaingan, kebijakan dan peraturan pemerintah termasuk ekonomi makro dan mikro, sosial budaya, demografi, hukum, politik dan teknologi (Suyanto, 2007).

Evaluasi faktor internal dan eksternal dengan pendekatan analisis SWOT untuk menyusun strategi pemasaran melalui empat pilar utama yaitu kekuatan dan kelemahan serta peluang dan ancaman. Keunggulan perusahaan dapat diidentifikasi dengan kekuatan dan kelemahan (faktor internal) yang dapat mengukur kemampuan bersaing dan pengelolaan sumber daya dalam menjalankan usaha. Sedangkan faktor peluang dan ancaman (faktor eksternal) adalah perkembangan politik, ekonomi, sosial dan teknologi, kondisi sosial yang berubah-ubah (Andriani, et, al., 2017). Lima komponen keunggulan bersaing yaitu Cost (Biaya), Quality (Mutu), Flexibility (Fleksibilitas), Delivery (Pengiriman) dan Innovation (Inovasi) (Russell \& Millar, 2014). Strategi manajemen pasca pandemi COVID-19 implementasi strategi pemasaran sebagai upaya untuk menciptakan eksistensi bisnis usaha yang lebih efisien dan efektif bagi pelaku UMKM sehingga memiliki manajemen pengetahuan yang baik dan absorptive capacity untuk meningkat kinerja bisnisnya (Fitriyani, Sudiyarti, \& Fietroh, 2020).

Pendekatan sistematis dalam mendukung pengambilan keputusan adalah dengan menganalisis lingkungan eksternal dan internal secara bersamaan dengan menggunakan analisis SWOT (Filbert, et, al., 2018). Analisis SWOT digunakan untuk analisis faktor internal dan eksternal dengan tujuan mengetahui posisi perusahaan berdasarkan kekuatan, kelemahan, peluang dan ancaman yang dihadapi perusahaan (Winarni, Wisnubroto, \& Suyatno, 2013). Analisis SWOT adalah identifikasi berbagai faktor yang disusun secara sistematis untuk merumuskan strategi perusahaan yang didasarkan pada logika yang dapat menganalisis kekuatan (Strength) dan peluang (Opportunity), namun secara bersamaan dapat meminimalkan kelemahan (Weakness) dan ancaman (Threat) (Kotler \& Keller, 2006).

Analytical Hierarchy Process (AHP) digunakan para pengambil keputusan untuk menganalisis berbagai pilihan prioritas dengan multi kriteria (Rohmatulloh \& Winarni, 2012). AHP merupakan alat pengambil keputusan yang menguraikan suatu permasalahan kompleks dalam struktur hirarki dengan banyak tingkatan yang terdiri dari tujuan, kriteria, dan alternatif (Hardiyansyah, Ikhwana, \& Kurniawati, 2015). AHP melakukan perbandingan berpasangan untuk menilai alternatif di tingkat hirarki terendah secara berurutan untuk membuat keputusan terbaik di antara alternatif (Görener, Toker, \& Uluçay, 2012).

Metode kombinasi SWOT dan AHP digunakan untuk menganalisis dan mencari strategi pemasaran yang terbaik untuk 
meningkatkan produktivitas pemasaran pada perusahaan (Pradipta, Suaedi, \& Dewa, 2019). Akhir dari proses AHP adalah prioritas-prioritas dari alternatif-alternatif prioritas tersebut dapat digunakan untuk menentukan alternatif terbaik (Istianingsih, Salim, \& Defit, 2019). Tujuannya penggunaan AHP adalah untuk memperoleh prioritas strategi dari beberapa alternatif strategi yang dihasilkan dalam matriks SWOT untuk peningkatan daya saing UMKM (Mustaqim, Kusnandar, \& Agustono, 2018).

Tujuan penelitian ini adalah melakukan identifikasi terhadap faktor internal dan eksternal menggunakan pendekatan analisis SWOT dengan empat perspektif yaitu kekuatan dan kelemahan serta peluang dan ancaman. Hasil dari analisis SWOT adalah strategi yang disusun untuk penguatan strategi pemasaran UMKM Pudak Gresik. Matrik SWOT dipilih dengan menentukan bobot alternatif kriteria sebagai perumusan strategi terpilih menggunakan Analytical Hierarchy Process (AHP) untuk meningkatkan keunggulan bersaing usaha Mikro Kecil Menengah (UMKM) Kota Gresik.

\section{METODE PENELITIAN}

Penelitian diawali dengan melakukan wawancara terhadap para pelaku UMKM Pudak tentang kondisi saat ini di tengah kondisi pandemi COVID-19 dan penyebaran kuesioner untuk mengetahui faktor kekuatan, kelemahan, peluang dan ancaman terhadap pemasaran produk Pudak Gresik. Pengumpulan data dilakukan dengan teknik purposive sampling dengan memberikan kuesioner kepada 50 responden yang terdiri dari pelaku UMKM, kelompok usaha, pemerintah dan konsumen Pudak Kota Gresik. Selanjutnya pemberian skor dilakukan oleh pihak expert untuk mengetahui bobot masing-masing kriteria dalam menentukan strategi terpilih.

Tahap selanjutnya penyusunan faktor internal dan eksternal dengan menggunakan SWOT analisis yaitu menyusun faktor kekuatan dan kelemahan serta peluang dan ancaman. Kemudian dari penyusunan faktor internal dan eksternal tersebut disusun matrik IFAS (internal strategic factor analysis summary) dan matrik EFAS (external strategic factor analysis summary). Untuk mengetahui posisi perusahaan maka disusun matrik IE (Internal Eksternal). Selanjutnya yaitu disusun matrik SWOT yang menghasilkan empat alternatif strategi untuk membantu UMKM dalam menentukan strategi yang tepat, yaitu strategi SO (StrengthOpportunities), ST (Strength-Threats), WO (Weakness-Opportunities), WT (WeaknessThreats).
Tabel 1. SWOT strategic issues

\begin{tabular}{l|ll}
\hline \multicolumn{1}{c|}{ Internal } & Strenght (S): & Weak (W): \\
& 1. & 1. \\
& 2. & 2. \\
\hline Threat (T): & Strategi ST & Strategi WT \\
1. & Gunakan S & Minimalkan W \\
2. & untuk & dan hindari T \\
Opportunity & Strategi SO & Strategi WO \\
(O): & Gunakan S & Atasi W \\
1. & untuk & dengan \\
2. & memanfaatkan & memanfaatkan \\
& O & O \\
\hline
\end{tabular}

Sumber: Lukmandono (2015)

Metode AHP digunakan untuk mendukung pengambilan keputusan dengan multikriteria. Penentuan bobot masing-masing faktor dari strategi SWOT kemudian disusun perbandingan berpasangan untuk menentukan tingkat kepentingan setiap alternatif strategi, sehingga diperoleh strategi prioritas untuk penguatan pemasaran UMKM Pudak Gresik. Sedangkan hirarki SWOT AHP ditunjukan pada Gambar 1.

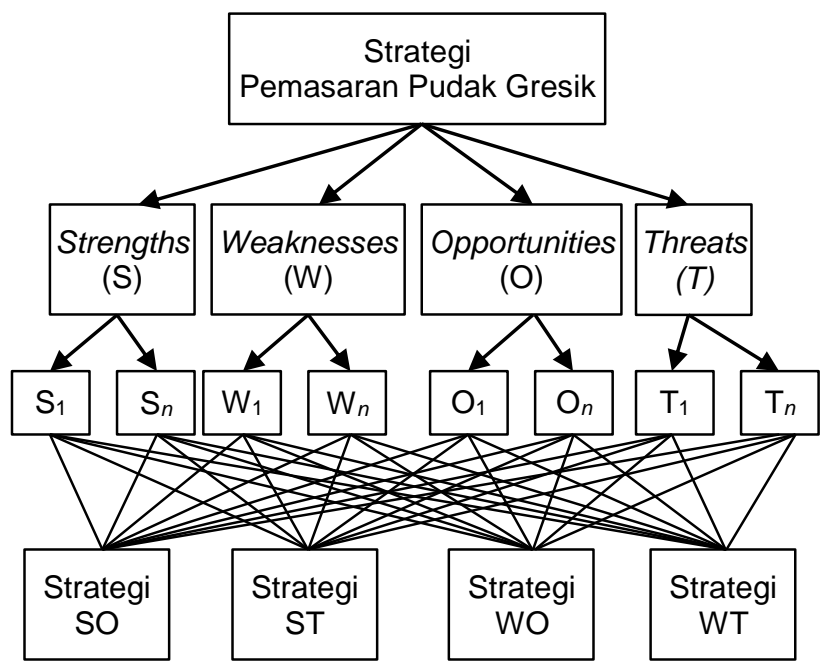

Gambar 1. Hirarki SWOT AHP strategi pemasaran Pudak Gresik

\section{HASIL DAN PEMBAHASAN}

Hasil wawancara dan penyebaran kuesioner terhadap pelaku usaha, kelompok usaha, pemerintah dan konsumen digunakan untuk menyusun faktor-faktor kekuatan, kelemahan, peluang dan ancaman UMKM Pudak Gresik. Langkah selanjutnya yaitu penyusunan matrik IFAS sebagai penjabaran dari kondisi internal UMKM Pudak Gresik dijabarkan pada kekuatan dan kelemahan yang menunjukan nilai bobot dan rating masing-masing faktor (Tabel 2) dengan hasil skor peluang pada tabel 2 sebesar 
1,7394 dan skor kelemahan sebesar 0,9619 sehingga diperoleh skor total faktor internal sebesar 2,7013.

Tabel 2. Matrik IFAS untuk UMKM Pudak Gresik

\begin{tabular}{|c|c|c|c|c|}
\hline No & $\begin{array}{l}\text { Faktor - faktor } \\
\text { Internal }\end{array}$ & Bobot & Rating & Skor \\
\hline \multicolumn{5}{|c|}{ Kekuatan } \\
\hline 1 & $\begin{array}{l}\text { Harga terjangkau } \\
\text { Kualitas dan rasa }\end{array}$ & 0,1185 & 3 & 0,3555 \\
\hline 2 & terjamin & 0,1071 & 2 & 0,2143 \\
\hline 3 & $\begin{array}{l}\text { Potongan harga bila } \\
\text { membeli banyak } \\
\text { Sudah mulai dikenal }\end{array}$ & 0,1031 & 4 & 0,4123 \\
\hline 4 & luas & 0,0763 & 3 & 0,2289 \\
\hline 5 & Usaha turun temurun & 0,1047 & 2 & 0,2094 \\
\hline 6 & $\begin{array}{l}\text { Produk tanpa bahan } \\
\text { pengawet }\end{array}$ & 0,1063 & 3 & 0,3190 \\
\hline Sub & tal & 0,6161 & & 1,7394 \\
\hline \multicolumn{5}{|c|}{ Kelemahan } \\
\hline 1 & Manajemen tradisional & 0,0625 & 2 & 0,1250 \\
\hline 2 & $\begin{array}{l}\text { Sarana dan prasarana } \\
\text { yang sederhana }\end{array}$ & 0,0657 & 3 & 0,1972 \\
\hline 3 & Satu varian rasa & 0,0609 & 2 & 0.1218 \\
\hline 4 & $\begin{array}{l}\text { Fluktuasi harga di toko } \\
\text { lain }\end{array}$ & 0,0674 & 3 & 0,2021 \\
\hline 5 & Dijual di toko sendiri & 0,0609 & 3 & 0,1826 \\
\hline 6 & $\begin{array}{l}\text { Produk hanya bertahan } \\
\text { tiqa hari }\end{array}$ & 0,0666 & 2 & 0,1331 \\
\hline \multicolumn{2}{|c|}{ Subtotal } & 0,3839 & & $\begin{array}{l}0,9619 \\
27013\end{array}$ \\
\hline
\end{tabular}

Tabel 3. Matrik EFAS untuk UMKM Pudak Gresik

\begin{tabular}{|c|c|c|c|c|}
\hline No & $\begin{array}{c}\text { Faktor - faktor } \\
\text { Eksternal }\end{array}$ & Bobot & Rating & Skor \\
\hline \multicolumn{5}{|c|}{ Peluang } \\
\hline 1 & $\begin{array}{l}\text { Pangsa pasar yang } \\
\text { masih luas }\end{array}$ & 0,1172 & 3 & 0,3515 \\
\hline 2 & Potensi lebih luas & 0,1179 & 3 & 0,3536 \\
\hline 3 & $\begin{array}{l}\text { Keuntungan sangat } \\
\text { menjanjikan }\end{array}$ & 0,11 & 3 & 0,3305 \\
\hline 4 & $\begin{array}{l}\text { Program } \\
\text { pemerintah dalam } \\
\text { mendukung } \\
\text { pariwisata }\end{array}$ & 0,1151 & 4 & 0,4603 \\
\hline 5 & $\begin{array}{l}\text { Tingginya loyalitas } \\
\text { konsumen terhadap } \\
\text { produk }\end{array}$ & 0,1137 & 3 & 0,3410 \\
\hline 6 & $\begin{array}{l}\text { Dibukanya jual beli } \\
\text { online }\end{array}$ & 0,1123 & 2 & 0,2245 \\
\hline \multicolumn{2}{|c|}{$\begin{array}{l}\text { Subtotal } \\
\text { Ancaman }\end{array}$} & 0,6862 & & 2,0614 \\
\hline 1 & $\begin{array}{l}\text { Munculnya pesaing } \\
\text { baru }\end{array}$ & 0,0614 & 2 & 0,1227 \\
\hline 2 & $\begin{array}{l}\text { Pelepah aren } \\
\text { Susah didapat }\end{array}$ & 0,0656 & 3 & 0,1967 \\
\hline 3 & $\begin{array}{l}\text { Munculnya varian } \\
\text { rasa baru }\end{array}$ & 0,0628 & 4 & 0,2510 \\
\hline 4 & $\begin{array}{l}\text { Kenaikan harga } \\
\text { bahan dasar } \\
\text { tepung beras }\end{array}$ & 0,0642 & 2 & 0,1283 \\
\hline 5 & $\begin{array}{l}\text { Sistem distribusi } \\
\text { terhambat adanya } \\
\text { pandemi }\end{array}$ & 0,0600 & 3 & 0,1799 \\
\hline \multicolumn{2}{|c|}{ Subtotal } & $\begin{array}{c}0,3138 \\
1\end{array}$ & & $\begin{array}{l}0,8787 \\
2,9400\end{array}$ \\
\hline
\end{tabular}

Langkah penyusunan matrik EFAS untuk pemetaan kondisi eksternal UMKM Pudak Gresik melalui faktor peluang dan ancaman. Matrik ini menggambarkan kondisi peluang usaha yang dimiliki oleh UMKM Pudak Gresik dan ancaman yang dihadapi dalam pemasaran produk (Tabel 3). Hasil matrik EFAS menunjukkan hasil skor peluang pada tabel 3 sebesar 2,0614 dan ancaman sebesar 0,8787 sehingga diperoleh total skor faktor eksternal sebesar 2,9400.

Setelah disusun matrik IFAS dan EFAS, selanjutnya yaitu menyusun matrik IE (Internal Eksternal) untuk mengetahui kondisi UMKM Pudak Gresik. Matrik ini sebagai langkah awal dalam penyusunan strategi alternatif penguatan pemasaran untuk keunggulan bersaing. Nilai IFAS sebesar 2,7013 berada pada tingkat ratarata yaitu antara nilai $2,00-3,00$. Sedangkan nilai skor EFAS juga berada pada tingkat menengah yaitu 2,9400 (Gambar 2). Hasil penyusunan matrik IE (Internal Eksternal) diketahui bahwa UMKM Pudak Gresik berada pada kuadran $\mathrm{V}$ yang artinya penyusunan strategi alternatif mengarah pada penerapan strategi pertumbuhan dan stabilitas.

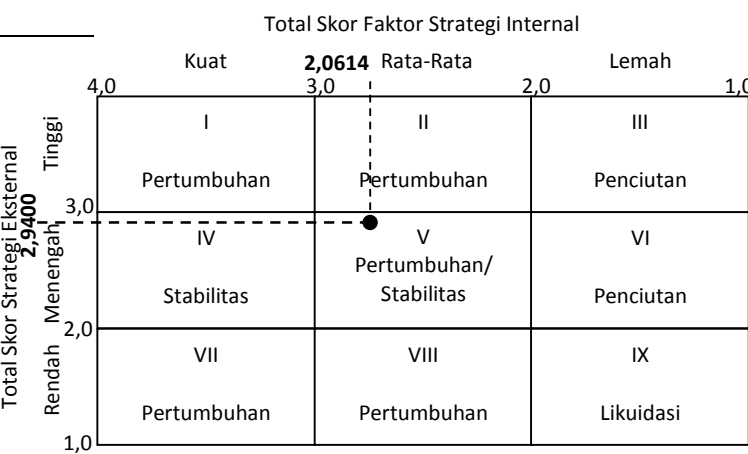

Gambar 2. Matrik IE UMKM Pudak Gresik

Setelah diperoleh strategi dari empat perspektif di matriks SWOT (Tabel 4), tahap selanjutnya yaitu menentukan prioritas dari masing-masing strategi alternatif yang ada. Penyusunan hirarki dimulai dari tujuan sebagai goal strategi penguatan pemasaran UMKM Pudak Gresik, kemudian empat perspektif dari kekuatan, kelemahan, peluang dan ancaman sebagai kriteria. Masing-masing faktor internal dan eksternal sebagai sub kriteria. Sedangkan hasil penyusunan strategi pada matriks SWOT digunakan sebagai alternatif yang akan dipilih melalui pembobotan perbandingan berpasangan dalam model AHP yang telah dilakukan melalui expert judgment. 
Tabel 4. Matrik SWOT UMKM Pudak Gresik

\begin{tabular}{|c|c|c|}
\hline IFAS & $\begin{array}{l}\text { Strenghts (S) } \\
\text { 1. Harga terjangkau } \\
\text { 2. Kualitas dan rasa terjamin } \\
\text { 3. Potongan harga bila membeli banyak } \\
\text { 4. Sudah mulai dikenal luas } \\
\text { 5. Usaha turun temurun } \\
\text { 6. Produk tanpa bahan pengawet }\end{array}$ & $\begin{array}{l}\text { Weaknesess }(\mathbf{W}) \\
\text { 1. Manajemen tradisional } \\
\text { 2. Sarana dan prasarana yang } \\
\text { sederhana } \\
\text { 3. Satu varian rasa } \\
\text { 4. Fluktuasi harga di toko lain } \\
\text { 5. Dijual di toko sendiri } \\
\text { 6. Produk hanya bertahan tiga hari }\end{array}$ \\
\hline $\begin{array}{l}\text { Oportunities }(\mathbf{O}) \\
\text { 1. Pangsa pasar yang masih luas } \\
\text { 2. Potensi lebih luas } \\
\text { 3. Keuntungan sangat menjanjikan } \\
\text { 4. Program pemerintah dalam } \\
\text { mendukung pariwisata } \\
\text { 5. Tingginya loyalitas konsumen } \\
\text { terhadap produk } \\
\text { 6. Dibuka jual beli online }\end{array}$ & $\begin{array}{l}\text { Strategi S-O } \\
\text { 1.Mempertahankan harga dan } \\
\text { meningkatkan kualitas produk tanpa } \\
\text { bahan pengawet untuk meningkatkan } \\
\text { loyalitas konsumen terhadap produk } \\
\text { dan memperoleh keuntungan yang } \\
\text { menjanjikan. (S1, S2, S6, O3, O5) } \\
\text { 2. Melakukan promosi dan memberi } \\
\text { diskon agar lebih dikenal luas (S3, S4, } \\
\text { O6) } \\
\text { 3.Mempertahankan usaha turun temurun } \\
\text { untuk mendukung program pemerintah } \\
\text { dan memenuhi pangsa pasar yang luas } \\
\text { (S5, O1, O4, O6) }\end{array}$ & $\begin{array}{l}\text { Strategi W-O } \\
\text { 1. Merubah manajemen tradisional } \\
\text { menjadi manajemen modern untuk } \\
\text { memenuhi pangsa pasar yang } \\
\text { memiliki potensi lebih luas (W1, O1, } \\
\text { O2) } \\
\text { 2. Memperbaiki sarana dan prasarana } \\
\text { untuk mendukung program } \\
\text { pemerintah dan menarik minat } \\
\text { wiasatan yang berkunjung di kota } \\
\text { Gresik (W2, O4) } \\
\text { 3. Mengembangkan varian produk } \\
\text { baru untuk memenuhi pangsa pasar } \\
\text { dan meningkatkan keuntungan (W3, } \\
\text { O1, O3) } \\
\text { 4. Memberikan pelayanan terbaik } \\
\text { kepada konsumen untuk } \\
\text { meningkatkan loyalitas konsumen } \\
\text { terhadap produk (W5, O5) }\end{array}$ \\
\hline $\begin{array}{l}\text { Treathts }(\mathrm{T}) \\
\text { 1.Munculnya pesaing baru } \\
\text { 2.Pelepah aren susah didapat } \\
\text { 3. Munculnya varian rasa baru } \\
\text { 4. Kenaikan harga bahan dasar tepung } \\
\text { beras } \\
\text { 5. Sistem distribusi terhambat adanya } \\
\text { pandemi }\end{array}$ & $\begin{array}{l}\text { Strategi S-T } \\
\text { 1.Mempertahankan kestabilan harga dan } \\
\text { efisiensi penggunaan bahan baku ( } \mathrm{S} 1 \text {, } \\
\text { T2, T4) } \\
\text { 2.Menciptakan varian rasa baru dengan } \\
\text { kualitas dan rasa terjamin untuk } \\
\text { bersaing dengan varian baru yang ada } \\
\text { di toko lain (S2, T1, T3) } \\
\text { 3.Menjual produk ke luar kota Gresik } \\
\text { agar dikenal luas melalui jual beli online } \\
\text { (S4, T5) }\end{array}$ & $\begin{array}{l}\text { Strategi W-T } \\
\text { 1. Melakukan inovasi terhadap produk } \\
\text { agar lebih tahan lama dan memiliki } \\
\text { varian rasa lebih banyak (S3, S6, } \\
\mathrm{T} 1, \mathrm{~T} 3) \\
\text { 2. Mempertahankan harga dan } \\
\text { efisiensi penggunaan bahan dasar } \\
\text { dan pendukung }(\mathrm{S} 4, \mathrm{~T} 2, \mathrm{~T} 4)\end{array}$ \\
\hline
\end{tabular}

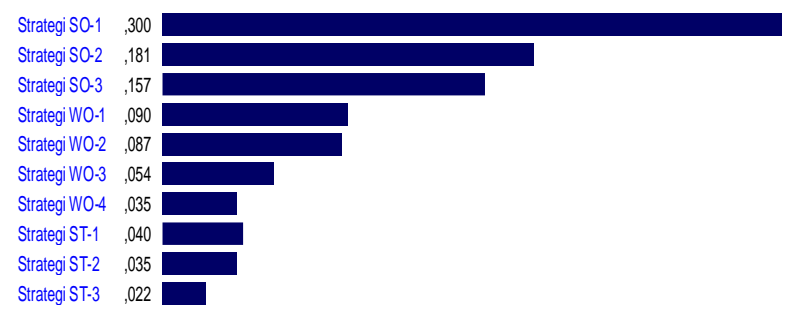

Gambar 3. Bobot prioritas alternatif strategi pemasaran UMKM Pudak Gresik

Alternatif strategi terbaik untuk meningkatkan keunggulan bersaing melalui penguatan strategi pemasaran UMKM Pudak Gresik (Gambar 3) yaitu strategi SO-1 mempertahankan harga yaitu Rp. $2.500-5.000$ rupiah per bungkus. Penggunaan bahan baku tanpa bahan pengawet untuk meningkatkan loyalitas konsumen terhadap produk, hal ini dipilih untuk memberikan rasa dan aroma yang khas terhadap hasil produksi. Meningkatkan keuntungan sebesar $23 \%$ dari yang sebelumnya hanya $7 \%$, dengan nilai bobot sebesar 0,300 . Penggunaan bahan baku tanpa bahan pengawet secara tidak langsung akan mempengaruhi pelanggan dalam mendapatkan produk yang higienis (Alfarisi, 2018; Riskiawan, Wibowo, \& Ariyati, 2017) Sedangkan untuk prioritas kedua yaitu strategi SO-2 melakukan promosi melalui paguyuban dan kelompok UMKM tingkat Kabupaten dan daerah, pengembangan media promosi berbasis online dengan menggandeng layanan pembelian berbasis aplikasi. Penggunaan aplikasi memberikan peluang untuk memperluas jangkauan pasar (Slamet, et, al., 2016) dan menjadi media penting untuk berkomunikasi dengan pelanggan seperti pada masa COVID yang interaksi dengan pelanggan menjadi terbatas. Memberikan potongan harga khusus setiap pembelian bagi konsumen dari kalangan perusahaan dan instansi tertentu yang membeli dalam jumlah banyak atau partai besar diatas 500 bungkus, cara ini dilakukan agar lebih dikenal luas dan menarik minat para konsumen diluar kota Gresik. 


\section{KESIMPULAN}

Berdasarkan hasil analisis yang dilakukan diperoleh kondisi UMKM Pudak Gresik berada pada pertumbuhan dan stabilitas yang membutuhkan strategi pemasaran yang membutuhkan penguatan internal melalui keunggulan bersaing sehingga pengembangan usaha dapat dilakukan. Strategi alternatif yang menjadi prioritas adalah mempertahankan harga produk dan meningkatkan kualitas untuk memperoleh loyalitas konsumen. Hal ini membutuhkan segmentasi dan segementasi pasar dengan peningkatan promosi melalui media online. Penguatan pemasaran juga harus didukung adanya inovasi dan pengembangan produk yang sesuai dengan kebutuhan dan keinginan konsumen. Penelitian ini dapat dilanjutkan dengan pendampingan implementasi kedua strategi terpilih untuk memberikan dampak nyata bagi UMKM Pudak Gresik.

\section{DAFTAR PUSTAKA}

Abdika, B. (2014). Analisis Formulasi Penentuan Prioritas Strategi Pemasaran UMKM Dengan Menggunakan Pendekatan Analisis SWOT Dan AHP (Studi Kasus Pada UMKM Penghasil Kerajinan Sulam Usus Aan Ibrahim). Skripsi. Universitas Lampung. Retrieved http://digilib.unila.ac.id/4460/.

Alfarisi, E. L. S. (2018). Faktor-Faktor yang Mempengaruhi Loyalitas Pelanggan(Studi kasus pada pabrik tahu goreng $\mathrm{H}$. Mahpud di Desa Langensari Kecamatan Karangtengah Kabupaten Cianjur). AGROSCIENCE (AGSCI), 3(1), 1-8. Retrieved from https://jurnal.unsur.ac.id/agroscience/article/ view/288.

Andriani, F. Y., Astari, D. I., Budhiarti, D., \& Zachary, K. M. (2017). Analisis Pengambilan Keputusan Strategi Pengembangan Industri Kreatif Kulit Ikan Pari Yogyakarta Dengan Pendekatan SWOT Dan AHP. In Seminar Nasional IENACO (pp. 288-295). Solo: Universitas Muhammadiyah Surakarta. Retrieved from https://publikasiilmiah.ums.ac.id/xmlui/handl e/11617/8664.

Filbert, E., Zaman, A. N., Prabowo, A. R., Nabila, F., \& Chalifah, R. D. (2018). Kajian Strategi Pengembangan Usaha Pada Industri konveksi" Scouth Shop" di Cibubur. In Seminar dan Konferensi Nasional IDEC ISSN (pp. 2579-6429). Universitas Sebelas Maret Surakarta. Retrieved from https://idec.ft.uns.ac.id/wp-
content/uploads/2018/05/ID036.pdf.

Fitriyani, I., Sudiyarti, N., \& Fietroh, M. N. (2020). Strategi Manajemen Bisnis Pasca Pndemi Covid-19. Indonesian Journal of Social Sciences and Humanities, 1(2), 87-95. https://doi.org/10.15797/concom.2019..23.0 09.

Görener, A., Toker, K., \& Uluçay, K. (2012). Application of Combined SWOT and AHP: A Case Study for a Manufacturing Firm. Procedia - Social and Behavioral Sciences, 58 , $1525-1534$. https://doi.org/10.1016/j.sbspro.2012.09.113 9.

Hardiyansyah, A., Ikhwana, A., \& Kurniawati, R. (2015). Analisis Strategi Pemasaran Usaha Mie Basah (Studi Kasus Di PD. Lugina Garut). Jurnal Algoritma Sekolah Tinggi Teknologi Garut, 13(1), 1-13. Retrieved from

https://sttgarut.ac.id/jurnal/index.php/kalibra si/article/view/233.

Hartanto, A. B., \& Kholil, M. (2018). Analisis SWOT Sebagai Dasar Perumusan Strategi Pemasaran (Studi Kasus: Pada Perusahaan Trading PT. PTG). Jurnal Rekayasa Teknologi Industri Hijau, 1(2), 1$5 . \quad$ Retrieved from https://ejournal.unugha.ac.id/index.php/ratih /article/view/54.

Istianingsih, N., Salim, E., \& Defit, S. (2019). Strategi Sustainability UMKM Pisang Sale di Kabupaten Bungo dengan Metode SWOT dan Analytic Hierarchy Process (AHP). In Prosiding Seminar Nasional Riset Information Science (SENARIS) (pp. 110118). STIKOM Tunas Bangsa. https://doi.org/10.30645/senaris.v1i0.14

Kotler, P., \& Keller, K. L. (2006). Marketing management. Prentice Hall. Retrieved from Google Scholar.

Lukmandono. (2015). Analisis SWOT Untuk Menentukan Keunggulan Strategi Bersaing Di Sektor Industri Manufaktur. In Industrial Engineering Conference (pp. 43-50). Universitas Sebelas Maret Surakarta. Retrieved from http://jurnal.itats.ac.id/2analisis-swot-untuk-menentukankeunggulan-strategi-bersaing-di-sektorindustri-manufaktur/.

Mustaqim, F. K., Kusnandar, K., \& Agustono, A. (2018). Analisis Kelembagaan Dan Strategi Peningkatan Daya Saing UMKM Emping Melinjo Di Kabupaten Magetan. SEPA: Jurnal Sosial Ekonomi Pertanian Dan Agribisnis, 14(2), 124-134. https://doi.org/10.20961/sepa.v14i2.25002. 
Pradipta, Z. H. A., Suaedi, D. A., \& Dewa, W. A. (2019). Analisis Strategi Pemasaran Menggunakan Metode Kombinasi SWOT (Strength, Weakness, Opportunity, Threats) Dan AHP (Analytical Hierarchy Process). Jurnal Teknologi Informasi, 2(1), 27-36. Retrieved from http://ejurnal.stimata.ac.id/index.php/TI/articl e/view/348.

Putra, D. S., \& Djazuli, A. (2013). Pengaruh Strategi Resource-Based terhadap Keunggulan Bersaing yang Dimediasi oleh Orientasi Kewirausahaan (Studi pada Usaha Kecil Menengah Sasirangan Kota Banjarmasin). Jurnal Aplikasi Manajemen, 11(3), 392-398. Retrieved from https://jurnaljam.ub.ac.id/index.php/jam/artic le/view/122.

Riskiawan, Y., Wibowo, E. A., \& Ariyati, Y. (2017). Analisis pengaruh brand perceived value awareness, perceived quality terhadap loyalitas pelanggan pada produk bumbu masak kokita di kota batam. EQUILIBIRIA, 4(1), 1-33. Retrieved from https://www.journal.unrika.ac.id/index.php/e qui/article/view/768.

Rohmatulloh, \& Winarni, S. (2012). Evaluasi Prioritas Strategi SWOT dengan Analytical Hierarchy Process. In Seminar Nasional Statistika III (pp. 1-8). Bandung: Jurusan Statistika Universitas Padjajaran. Retrieved from http://prosiding.statistics.unpad.ac.id/index. php/prosiding/article/view/sns3-SM1.

Russell, S. N., \& Millar, H. H. (2014). Competitive priorities of manufacturing firms in the Caribbean. IOSR Journal of Business and Management, 16(10), 72-82. Retrieved from https://www.iosrjournals.org/iosrjbm/papers/Vol16-issue10/Version1//0161017282.pdf.

Slamet, R., Nainggolan, B., Roessobiyatno, R., Ramdani, H., \& Hendriyanto, A. (2016). Strategi Pengembangan UKM Digital dalam Menghadapi Era Pasar Bebas. Jurnal Manajemen Indonesia, 16(2), 136-147. https://doi.org/https://doi.org/10.25124/jmi.v 16i2.319.

Sutanto, H. A., Sudantoko, D., \& Maktub, S. (2012). Strategi Peningkatan Keberdayaan Industri Kecil Konveksi Dengan Analiysis Hierarchy Process (AHP). JEJAK: Jurnal Ekonomi Dan Kebijakan, 5(1), 15-25. Retrieved from https://journal.unnes.ac.id/nju/index.php/jeja k/article/view/4623.

Suyanto, M. (2007). Marketing Strategy Top Brand Indonesia. Penerbit Andi. Retrieved from Google Scholar.

Winarni, Wisnubroto, P., \& Suyatno. (2013). Perencanaan Strategi Pemasaran Melalui Metode SWOT Dan BCG Guna Menghadapi Persaingan Dan Menganalisis Peluang Bisnis. In Jurnal Diterbitkan (pp. 226-237). Jogyakarta: Institut Sains dan Teknologi AKPRIND Jogyakarta. Retrieved from

http://eprints.dinus.ac.id/8066/1/jurnal_1249 2.pdf. 